\title{
A Rose by Any Other Name
}

\author{
James J. James, MD, DrPH, MHA
}

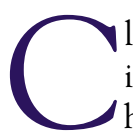

lassification is a fascinating topic, especially as it applies to disaster medicine and public health. In an overly simplified model we can classify either (1) objectively, such as by some numerical or distinctive aspect (eg, age or size) that allows for separation into distinct, measureable, and reproducible categories, or (2) subjectively, wherein we must use some selected cutoffs along a continuum to separate units with shared characteristics into subgroups with overall similarities, such as types of cheeses. (It is, of course, the latter [subjective] classification approach that we must, most often, deal with in our field, and all too often there is little or no agreement on either characteristics or cutoffs.) The related field of taxonomy deals more specifically with the nomenclature used to define those more or less subjective categories to better identify their characteristics, such as hard versus soft versus semisoft cheeses.

I go into this discourse to underscore the critical need to evolve a common classification and taxonomy system for disaster medicine and public health. Without such an advance, we will never achieve the discipline integration needed for success nor the research agenda necessary to define the foundational basics for effective policy and public health programs derived from and based on that policy. These thoughts have been echoed frequently by many others in the past and by such eminent individuals as Marv Birnbaum, ${ }^{1}$ former Editor in Chief of Prehospital and Disaster Medicine, and Skip Burkle, ${ }^{2}$ Senior Fellow and Scientist at the Harvard Humanitarian Initiative and a current editor of this journal, two of the most notable pioneers in the evolving discipline of Disaster Medicine and Public Health. It is now past time to make some progress in achieving these goals.

The need for this classification/taxonomic effort was underscored recently as we were having discussions regarding the themes and presentations planned for our 2 nd annual meeting later this year. A favorite, recurring discussion was a focus on responders, which was all well and good until it became obvious that there was little agreement as to what defines a responder. The ensuing discussions addressed first responders, individual versus group responders, volunteers, bystanders, nongovernmental organizations, uniformed and nonuniformed responders, and myriad other descriptive terms. The one thing we agreed on was the need for a taxonomy of responders so that there could be a common understanding of terms as well as the establishment of a basis for generating standards and permitting comparative research studies on performance, outcomes, and other important values. The conclusion of the discussion was a common decision to begin to establish the framework for such a taxonomy and to expand on it at this year's meeting.

Another area where further classification work is needed is in first generating a consensus definition of the overall meaning of disaster and the use of terms such as emergency, crisis, mass casualty, and socioeconomic disruption, which are often used interchangeably. We must work toward better refining the meaning of these terms so that we are more clearly grouping similar events and so that different users are in better agreement when describing an event, as to type, magnitude, impact, and timeline, much as we do in classifying and standardizing diagnostic codes.

Another factor that prompted this editorial lay in my wanting to present an update on current and ongoing disaster events and initiatives under way to make our journal more useful to those involved in responding to them. I first turned to EM-DAT, ${ }^{3}$ which was created with support from the World Health Organization and the Belgian government in 1988 and has compiled data on the occurrence and effects of over 18,000 mass disasters from 1900 to the present and is a very useful research tool, especially for the humanitarian community. The database although providing excellent research can be cumbersome and difficult to use, especially for the more current events, which makes it awkward to serve as a practical tool for public health preparedness and response. Without dwelling on other available databases, the one I found most useful and practical was Wikipedia. ${ }^{4}$

This source defined 7 subcategories of disasters for 2016 of which the following 6 events were reported: attacks (4), fires (1), natural (10), terrorist incidents (13), transportation (3), and health (3). Focusing on the health subcategory, the Flint water crisis, the West Africa Ebola epidemic, and the Zika virus outbreak are noted and quickly led to more extensive articles on each (note that the terms epidemic and 
outbreak were as listed in the website). Thus, this resource can be used to quickly access current information on current and ongoing health-related disasters, but does not provide the type of peer-reviewed data and information that can be used to guide evidence-based policy and public health interventions. This is the role of Disaster Medicine and Public Health Preparedness journal in this arena: the rapid publication of useful peerreviewed information and data as was done for the Ebola epidemic and is now being done with the emergence of Zika.

Of course, even though we must be more focused on ongoing health events, from an all-hazards perspective, we have to be concerned with and attentive to all subcategories of disasters. That has certainly been the direction taken and the foundation of our preparedness initiatives and, most importantly, in our education and training programs. This also reflects the growing awareness of the role of population health and the impact of external determinants in impacting each component of the disaster cycle (prevention, preparedness, response, recovery, and mitigation).

However, I do not believe we can ever achieve an effective all-hazards perspective without a corresponding all-discipline integration of efforts; otherwise, we will continue to waste energy and drain resources because of disconnected and overlapping missions. And that defines the role of, and need for, the Society for Disaster Medicine and Public Health. The first steps have been taken, but the need to draw together disparate organizations, disciplines, and perspectives into a collaborative learning community has never been clearer. To paraphrase the Bard, a disaster by any other name is still a disaster. A common Disaster Medicine and Global Health taxonomy will form the foundation of a safer, more resilient world, through more effective preparedness and response; but we must first truly come together for the public good.

\section{REFERENCES}

1. Birnbaum ML. Changing the taxonomy in public health and medicine. Disaster Med Public Health Prep. 2014;8(2):111. doi:10.1017/dmp.2014.35.

2. Burkle FM, Greenough PG. Impact of public health emergencies on modern disaster taxonomy, planning, and response. Disaster Med Public Health Prep. 2008;2(3):192-199. doi:10.1097/DMP.0b013e3181809455.

3. EM-DAT The International Disaster Database. General classification. http://www.emdat.be/classification. Accessed March 7, 2016.

4. Disaster. Wikipedia website. https://en.wikipedia.org/wiki/Disaster. Accessed March 7, 2016. 